\title{
La cal en Tenerife. Especificidades. El horno de EI Bueno-Arico y la producción de cal a partir del agua de galería
}

\section{$M^{a}$ Isabel Sánchez Bonilla ${ }^{a}$ y Tomás Oropesa Hernández}

${ }^{a}$ Universidad de La Laguna, C.U. Escultura, G.I. Arte y Entorno, Facultad de Bellas Artes, c/ Radioaficionados s/n, CP 38220, La Laguna, sbonilla@ull.edu.es, b Universidad de La Laguna, P.T Escultura, G.I. Arte y Entorno, Facultad de Bellas Artes, c/ Radioaficionados s/n, CP 38220, La Laguna, toropesa@ull.edu.es.

\begin{abstract}
Resumen
La isla de Tenerife, de origen volcánico, no cuenta con canteras de cal activas.

A nivel histórico se tienen noticias desde el siglo XVI y a lo largo de los cuatro siguientes, sobre la escasez de cal, su búsqueda en Taganana y Tejina y la existencia de cantera en Los Realejos. Lo habitual era la importación de la piedra cruda desde las Islas Orientales, o su llegada desde puertos españoles o europeos. Se menciona también (s. XVIII) la fabricación de cal a partir de "confites" (esqueletos de algas de la familia Corallinaceae). Otra experiencia singular es la obtención de cal (años 40 del siglo XX) a partir de sedimento depositado por aguas subterráneas carbonatadas.

Se hace análisis de los datos históricos disponibles, acompañado de trabajos de campo para validarlos, centrando finalmente el interés en el horno y decantador de "Mister Villa", ubicado en El Bueno-Arico, como experiencia que interesa tomar en consideración de cara a las investigaciones que actualmente viene desarrollando el G.I. Arte y entorno, creación, conservación, comunicación de la ULL, sobre posibilidades de aprovechamiento de las tobas y travertinos que depositan las aguas de múltiples galerías tinerfeñas, materiales que actualmente se consideran como residuos sin utilidad alguna.
\end{abstract}

Palabras clave: Tenerife, Arico, patrimonio, horno de cal, aguas subterráneas, tobas, residuos, medioambiente, sostenibilidad.

\begin{abstract}
Tenerife is a volcanic island that does not have active lime quarries.

We have news since sixteenth century and during the next four centuries, about the shortage of lime, its research at Taganana and Tejina, and the existence of a quarry in Los Realejos. It was common to import uncooked lime Stone from the easternmost islands, or the arrival of this material from Spanish or European ports. It is also mentioned (18th century) the manufacture of lime from "confites" (skeletons from algae of the Corallinaceae family). Another unique experience is to obtain lime (40s of the 20th century) from deposited sediment by carbonated groundwater.

We analyze the available historical data, accompanied by field work to validate them, finally focousing the interest on "Mister Villa"'s furnace and decanter, located at El Bueno-Arico, as an experience that we are considering interesting in relation to the research that the Research Group Arte y Entorno, Creación, Conservación, Comunicación, of ULL, are currently developing about possibilities of using the tuffs and travertines deposited by the groundwater in many galleries of Tenerife, materials that are currently considered as waste without any use.
\end{abstract}

Keywords: Tenerife, Arico, heritage, lime kiln, groundwater, tuffs, waste, environmental, sustainability. 


\section{Introducción}

La cal "a pesar de su carácter milenario es plenamente vigente e incluso imprescindible para la construcción en la sociedad actual preocupada, y con razón, del medioambiente y de las emisiones excesivas de CO2" (Argano, 2009), tomando como punto de partida esta frase de Sonia Argano, queremos destacar que la recuperación de la cal, a la que Sonia se refería como imprescindible hace diez años, hoy se ha de considerar además urgente, para su uso en morteros de alta durabilidad, aplicables tanto en restauración como en obra nueva, y como alternativa posible a los paramentos con acabados plásticos que de manera general venimos aplicando en la sociedad actual.

En la isla de Tenerife, la escasez de cal ha sido una constante histórica, resuelta a veces mediante importación, pero que en otras ocasiones ha llevado a reconocer y aprovechar recursos alternativos, entre ellos la obtención de carbonatos por decantación directa objeto del presente estudio, que pudiera ser un precedente de alto valor para resolver el problema medioambiental que en la actualidad suponen los residuos depositados por el agua de algunas galerías.

Nuestra aportación es, por tanto, no sólo recuperación del conocimiento histórico y puesta en valor de elementos patrimoniales poco conocidos, sino también una apuesta de futuro, de acercamiento a posibles soluciones para un problema actual de residuos, que nosotros queremos entender como materias útiles y oportunidad de desarrollo local.

Para la presentación del tema, se han considerado los siguientes bloques temáticos:

- La cal: origen, tipologías.

- Los materiales carbonáticos en Canarias-Tenerife.

- Referencias históricas sobre canteras y hornos de cal (siglos XVI a XX, materias primas y hornos, considerando tanto la importación de material como la obtención a partir de recursos locales).

- Producción de cal a partir del agua de galería: horno y decantador de "Mister Villa" (mitad del siglo XX).

Los dos primeros epígrafes, realizados por compilación, tienen carácter introductorio, para los bloques siguientes se usa metodología múltiple: recopilación de datos, trabajos de campo para validarlos/actualizarlos y, análisis de tendencia.

Los apartados anteriores se completarán mediante:

- Conclusiones

- Referencias

\section{La cal: origen, tipologías}

La cal se obtiene deshidratando, mediante cocción, piedras calizas de mayor o menor pureza. Como resultado de la cocción se obtiene la "cal viva" cuya composición principal es oxido de calcio $(\mathrm{CaO})$, elemento que en contacto con el agua reacciona de manera violenta, alcanzando temperaturas de $90^{\circ} \mathrm{C}$, por lo que en el mercado la encontraremos habitualmente como "cal apagada", cuya composición es básicamente hidróxido de calcio $(\mathrm{Ca}(\mathrm{OH}) 2)$.

Todo estudio sobre la cal, debe tener en cuenta que este término abarca materias con características y aplicaciones distintas. Se diferencia en primer lugar entre cales hidráulicas y cales aéreas:

La cal hidráulica puede ser natural, obtenida a partir de piedras calcáreas que contienen silicatos, o artificial, que se obtiene añadiendo productos hidráulicos a cales aéreas. La cal hidráulica no se suele clasificar en función de su composición, se clasifica según su resistencia (compresión, a los 28 días).

Como precedente histórico de la cal hidráulica artificial se han de citar los morteros romanos, en los que se solía mezclar puzolana (cenizas volcánicas provenientes de Puzzoli, cerca de Nápoles).

La denominación cal hidráulica natural tiene origen, a principios del siglo XIX, en Francia, donde -como ocurre también en Bélgica y Alemania- las canteras de cal suelen producir rocas con contenidos en silicatos muy altos, en comparación con las canteras de Italia y España, que suelen ser de cal aérea.

La cocción de la cal hidráulica, requiere temperaturas de $1200^{\circ} \mathrm{C}$. 
La cal aérea se obtiene de "piedras calcíticas o dolomíticas más o menos puras, a una temperatura de $900-1000^{\circ} \mathrm{C}$ (baja emisión de CO2) (...) se clasifican a partir de su pureza en óxido de calcio, encontrando así las cales CL90, CL80 y CL70" (Guixeras y Argano, 2010).

Dado que el objeto de nuestra investigación son unas tobas y travertinos cuyo contenido en calcita-aragonito es casi del $100 \%$, merece la pena detenernos algo más en estas cales de gran pureza, especialmente en la cal aérea en pasta, también denominada cal grasa, cuya pureza mínima ha de ser del 95\%, siendo la única tipología que suele comercializarse en húmedo. Sobre este tipo de cal nos dicen Guixeras y Argano lo siguiente:

La cal aérea en pasta, conocida como cal grasa, es un material muy particular, cuyas características diferenciales son:

- $\quad$ Tiene calidad de piedra, porque al endurecer se transforma en piedra (Ca CO3).

- $\quad$ Es aérea, porque carbonata (endurece) con el CO2 de la atmósfera.

- Es natural, porque no se le agregan productos químicos.

- Es una pasta, ya que hidratada se mantiene en estado amorfo (Guixeras y Argano, 2010).

Nos hablan también de que estas cales tienen una gran elasticidad, que favorece la disolución del CO2, consiguiendo un endurecimiento homogéneo "que a su vez genera una estructura porosa cristalina, que caracteriza las pastas de cal aérea una vez endurecidas... la pasta se ha transformado en carbonato cálcico, como la piedra caliza a partir de la cual ha empezado todo el proceso de obtención de la cal (ciclo de la cal)" (Guixeras y Argano, 2010), se obtiene como resultado un material impermeable al agua líquida pero cuyos poros dejan circular el vapor de agua y como consecuencia tendremos la posibilidad de morteros o enfoscados con un magnífico comportamiento frente a humedades, con múltiples aplicaciones en restauración del patrimonio y también en nuevas construcciones, con la ventaja de aportar una baja conductividad térmica.

La cal ha sido, durante siglos, el material más usado por nuestra cultura, tanto a nivel constructivo como en acabados de paramentos, no obstante, la aparición del cemento portland, la relegó desde hace más de un siglo a un segundo término. Actualmente observamos un movimiento general por su recuperación, del que encontramos evidencias muy notables, a modo de ejemplo citar, su inclusión en el Plan Nacional de Arquitectura Tradicional y, a nivel específico, el notable empuje que se le ha dado desde el municipio de Morón de la Frontera (Sevilla) a raíz de la declaración de la Cal de Morón como Patrimonio Cultural Inmaterial por UNESCO (2011).

\section{Los materiales carbonáticos en Canarias-Tenerife}

Cualquier reflexión sobre materiales a realizar en relación con Tenerife y, en general, respecto del Archipiélago Canario, ha de tomar en consideración como elemento inicial el hecho de que nos encontramos en un territorio conformado en su totalidad por estructuras volcánicas, siendo la isla más antigua Fuerteventura y la más joven El Hierro.

Como afirman Ana María Alonso Zarza y Álvaro Rodríguez Berriguete "Las Islas Canarias destacan por su enorme geodiversidad constituida de forma mayoritaria por los relieves volcánicos y sus formas de erosión, pero también por depósitos sedimentarios de enorme interés" (Martín-González et al., 2019, p. 9), entre ellos describen las calcretas o caliches y las tobas-travertinos; nos informan que las calcretas cubren gran parte de Lanzarote y Fuerteventura, conformando "una amplia cobertura de color blanquecino o beige que tapiza enormes áreas de estas islas, ocultando en muchas ocasiones los materiales volcánicos" (Ibídem, p. 10), mencionan como ejemplo los depósitos existentes en Mácher (Lanzarote) de 1,5 m. de espesor medio, desarrollados sobre basaltos; los depósitos de Tefía (Fuerteventura) de 1'75 m, sobre gravas aluviales formadas por materiales volcánicos; anotan también la presencia de calcretas en el Norte de Gran Canaria, poco desarrolladas, y en el Oeste de la Isla, en el área de Arinaga, donde "en ocasiones la superposición de distintos perfiles puede alcanzar cinco metros, desarrollados sobre rocas volcánicas, arenas o gravas" (Idem). No mencionan referencias similares en Tenerife, que tampoco hemos encontrado revisando bibliografía general y mapas geológicos de la isla.

Más adelante veremos imágenes de los autores del trabajo que podrían ser estímulo para estudios geológicos. 
Debido a la correspondencia entre los travertinos-tobas respecto al material objeto de estudio, nos interesa citar de manera amplia, lo que sobre ellos dicen Alonso Zarza y Rodríguez Berriguete:

"En este apartado nos referimos a depósitos carbonáticos con texturas variadas que se forman a partir de manantiales o surgencias (naturales o artificiales). El agua de estos manantiales ha circulado por las rocas volcánicas y tiene contenidos relativamente elevados en calcio y magnesio y además es rica en $\mathrm{CO} 2$, también de origen volcánico. En definitiva, tiene todos los componentes necesarios para que al aflorar en superficie y como resultado de la desgasificación se produzca la precipitación de carbonato en la salida del manantial y en los cursos de agua abastecidos por estos manantiales. Los términos travertino y toba se utilizan aquí como términos descriptivos. Travertino designa a depósitos de manantiales que son muy compactos, tienen poca porosidad y pocos restos biogénicos. Por el contrario, las tobas son muy porosas y tienen muchos restos vegetales o sus improntas. Es frecuente que, en las partes más proximales, cercanas a la salida de los manantiales termales, se formen travertinos; mientras que distalmente las aguas se enfrían, hay más vegetación y los depósitos característicos son tobas." (Ibídem, p. 12).

Sobre ubicaciones de este tipo de materiales, anotan como ejemplo: depósitos en los barrancos de Azuaje, Berrazales, y Temisas, todos ellos en Gran Canaria. Mencionan como caso particular los depósitos tobáceos antrópicos, formados a partir de manantiales artificiales utilizados para el regadío agrícola, localizados en el Barranco de Calabozo (Gran Canaria) debido a la salida de agua de una tubería de riego, probablemente activa entre 1950 y 1980, y como rasgo más característico de este depósito las cubiertas de calcita alrededor de los tallos vegetales.

En Tenerife contamos con múltiples depósitos de travertinos y tobas similares a los antes descritos, se aportan datos sobre precipitación anual e imágenes en el bloque 5 .

\section{Referencias Históricas sobre canteras y hornos de cal}

Pasamos ahora a revisar los datos disponibles a nivel histórico sobre la obtención de materiales carbonáticos (importados o locales) y su cocción (hornos locales).

Para facilitar la compresión del entorno específico y de su singularidad histórica (salto directo del Neolítico al Renacimiento) se incluyen previamente unas breves anotaciones sobre la Conquista.

Aunque se tienen referencias a contactos en la Época Romana y contamos con informaciones sobre el Archipiélago por parte de los árabes en la Edad Media, Canarias permaneció aislada culturalmente (fase Neolítica) hasta principios del siglo XIV, momento en que ya contamos con la primera visita documentada, de Lanceloto Malocelo a Lanzarote (1312); la primera cartografía de la isla es la Carta Portulano, de 1339, en la que aparece Lanzarote bajo bandera de Portugal; el conocimiento cartográfico de las Islas facilita sucesivas arribadas e intentos de control/conquista por parte de genoveses, aragoneses, castellanos y portugueses, quedando limitados en el siglo siguiente básicamente a castellanos y portugueses.

Como primer establecimiento en Gran Canaria, se tiene constancia de una misión franciscana en Telde (1350-1391). La primera misión franciscana en Tenerife se producirá en Candelaria-Menceyato de Güimar (1430-1478).

La conquista definitiva del Archipiélago se produjo en dos fases, la primera denominada de Señorío (1402-1405), en que los normandos dominan Lanzarote, El Hierro y Fuerteventura, produciéndose simultáneamente la conquista señorial castellana de La Gomera. La segunda fase, de conquista Realenga, se inicia en 1478, incorporando Gran Canaria (14781483), La Palma (1492-1493) y finalmente Tenerife, con un primer intento: Tratado de El Bufadero (1464), a raíz del cual, se edifica en Anaga una torre o castillo, que fue asediada y destruida hacia 1471-72 (Rumeu de Armas, 1975, p. 88). A partir de esta fecha, con la excepción del semicristianizado menceyato de Guimar, la isla de Tenerife se muestra "rebelde e impenetrable a la influencia europea" (Ibídem, p. 88) hasta la conquista definitiva, por el Adelantado Alonso Fernández de Lugo (1494-1496).

Para entender la evolución técnico-constructiva de Tenerife en los primeros años tras la Conquista, se ha de tener en cuenta, además de su paso directo desde la fase Neolítica a la Gótico-Renacentista, el hecho de que los conquistadores 
ya contaban con experiencia debida al asentamiento previo en el resto de las islas. No debe extrañarnos, por tanto, que en la primera época Tenerife recibiese tanto artesanos -con formación técnica castellano/lusa- como materiales -entre ellos piedra de cal- desde Gran Canaria, lugar de asentamiento previo del Adelantado, y desde Lanzarote o Fuerteventura, islas ya bien conocidas y que contaban con recursos significativos en cuanto a rocas carbonáticas.

\subsection{Importación de piedra de cal desde las Islas Orientales}

Aunque como veremos en el epígrafe siguiente, también se encuentras rocas calizas en Tenerife, dado que su importación presenta el mayor volumen, condicionando la ubicación de los hornos, se analizará este tema en primer lugar.

Todos los historiadores consultados coinciden en afirmar que "la roca de cal o travertinos calizos, abunda en las Islas Orientales y escasean en las restantes" (Martín, 1978, p. 70), llegando incluso a afirmarse que "la práctica inexistencia de piedra caliza en Tenerife provocó que desde un primer momento la isla se surtiera exclusivamente de este material mediante importaciones" (Larraz, 1998, p. 447). Todos los historiadores ofrecen también referencias sobre la existencia de hornos para su cocción en la propia isla, lo que resulta lógico teniendo en cuenta el peligro que podía comportar el transporte marítimo de "cal viva".

Contamos con datos sobre importación de piedra de cal desde Gran Canaria:

En octubre de 1514, los cabildeños deciden importar de Gran Canaria dos carabelas de caliza para ser quemada y abierta en un horno que, por cuenta del Ayuntamiento de la Isla, se estaba construyendo en Santa Cruz. En fechas sucesivas fueron llegando otros navíos con piedras rojizas o blancas, procedentes de la misma isla hermana, para ser quemadas en este mismo horno municipal" (Velázquez, 2001, p. 80).

Estas importaciones debieron ser habituales hasta 1531, fecha en que una Ordenanza prohibió sacar piedra de cal de la Isla sin licencia:

Otrosi que nynguno sea osado de sacar piedra de cal desta isla sin licencia de la cibdad so pena de dos mil maravedís por cada vez que fuere tomado e la piedra perdida... Otrosy que los dichos caleras vendan la cal regada y medida fría e no de otra manera so pena de perder la cal que de otra manera vendieren (Morales, 1974, p. 103).

Las importaciones desde Lanzarote y Fuerteventura constan desde principios del XVI y se suceden durante los siguientes ya que en "Lanzarote o Fuerteventura sobre todo, los señores no frenaban su exportación, sino que, al contrario, intentan impulsarla" (Martín, 1978, p. 70), consta igualmente la importación desde la España Peninsular, desde Portugal, desde otros países de Europa y desde América.

En varias ocasiones se importó cal de Portugal a Canarias... menor precio... en La laguna se empleó para blanquear cal de La Habana, en 1805, y cal de Londres, en 1870 (Martín, 1978, p. 71).

De Fuerteventura se sacaba la cal en la zona de Jandía al sur de la isla... Lanzarote tenía sus caleras principales en el Sur, en el lugar denominado Janubio (Idem.).

La piedra caliza para los hornos de la Caleta se embarcaba por el Puerto de Cabras (hoy del Rosario) y Gran Tarajal, en Fuerteventura, y por el de los Mármoles en Lanzarote. Venía transportada en barcos de cabotaje y pequeño tonelaje: "La Juanita", "El Cazón", "San Juan", "La Jara", "Zahara", "Daute", etc. y la desembarcaban por el muelle de Garachico, por el del Puertito de Daute y por la misma playa de La Caleta./ El navío fondeaba alejado de la costa, en el limpio, y a la pleamar la piedra era trasladada en lanchas de remo hasta la orilla de la playa, donde era tirada a la lengua del agua. Piedras que luego serían rescatadas a la mar vacía y cargadas a hombros o en carros, hasta el horno cercano (Velázquez, 2001, p. 82).

En cuanto a hornos, la referencia disponible más antigua es la siguiente: "Pedro de Sevilla traspasa a Diego Fernández sus derechos a la mitad de un sitio que ambos poseen en el camino de Guimar para hacer cal" (protocolos de Hernán Guerra, La Laguna 1508-1510). Se considera que el horno más activo de la época era el de Santa Cruz, que surtió cal para múltiples construcciones de San Cristóbal de La Laguna: 
Se estaba haciendo el horno de Santa Cruz por cuenta del Cabildo (18/05/1515, Serra y Ráfols, 1965 , p. VIII).

Se comete a Vergara y Gallinato que vean el edificio del horno de cal de Santa Cruz, porque allí se ha de cocer la cal de la Iglesia de los Remedios y la del Concejo y se pague el costo a sueldo por libra (Ibidem, p. $82)$.

Otros hornos históricos muy significativos se ubican en Garachico, Adeje, Los Realejos, Los Silos, etc.; estos hornos casi siempre los encontramos cercanos a la costa o junto a los caminos ascendentes que conectaban cada una de las principales poblaciones con sus respectivos puertos. También los había dentro de las poblaciones, aunque, como vemos en una de las citas siguientes, con el paso del tiempo se prohibiese esta ubicación. A modo de ejemplo vemos dos referencias sobre Garachico, principal puerto de la isla desde el siglo XVI hasta principios del XVIII.

(...) quema de la piedra de cal y obtención de ella en los dos hornos que humeaban a la orilla del mar: uno sobre la playa y muy cercano a la ermita de San Andrés y el otro dominando el caletón de la Potra, en la margen derecha del barranco y próximo a su desembocadura (...) Del primero de los hornos caleteros desconocemos su fecha de construcción, que contenía almacén para depositar la cal y casa habitación para el calero. Fue varias veces reconstruido y dejó de funcionar antes de 1920 (Velázquez, 2001, p. 82),

Queda prohibido establecer, dentro de la población, hornos o fábricas de cal y yeso, muladares, colmenas y todo otro artefacto o establecimiento que por su destino sea incómodo o insalubre o tenga que usar de materiales combustibles en grueso (Ordenanzas municipales de Garachico, redactadas entre mayo-agosto de 1874).

Como vemos en la primera de las citas anteriores, la actividad de los hornos de la Caleta de Interián (ubicada entre Garachico y Los Silos), se debió iniciar en la primera mitad del siglo XVI, coincidiendo la fundación de la Ermita de San Andrés, prolongándose hasta bien entrado el siglo XX. Cronologías similares concurren en la mayoría de los hornos históricos conservados, algunos de los cuales recuperarán su actividad tras la Guerra Civil, debido a la carestía de importaciones de cemento portland y la consiguiente necesidad que se tenía de aglomerantes hidráulicos.

\subsection{Canteras de cal en Tenerife}

Fernando Martín informa que, según consta en Data del Adelantado 168, las canteras de El Realejo se mencionan desde 1501, también transcribe que Cristóbal Trujillo de la Coba, en Cabildo-mayo-1601, informa que hay muchos caleros en los términos de Los Realejos y que en dicha fecha se autoriza a abrir caleras en esta zona, otorgando permiso a todos los que quisieran hacerlas. Estas citas, junto a las referencias de Velázquez Méndez a Garachico, Masca y Carrizales, llevan a pensar en una posible riqueza calera de la zona Noroeste de la isla. Es más, Viera y Clavijo (1731-1813) incluye en su Diccionario Natural de las Islas Canarias referencias a las canteras de cal de La Rambla (El Realejo), por lo que dicha actividad debió ser notoria al menos durante dos siglos.

(...) caleras del Realejo (...) se mencionan desde 1501 en las datas del Adelantado (...) 1601 (...) abrir caleras en esta zona... se otorga permiso a todos los que quisieren hacerlas (Martín, 1978, p.71).

En los valles de Masca y Carrizales (Buenavista del Norte), hubo varias canteras de calizas explotadas para erigir ingenios azucareros, levantar iglesias, ermitas, atarjeas para conducción de agua, casonas señoriales y las populares casas terreras de arcilla, caña y torta. / En 1520, Gonzálo Rodríguez, vecino de La Orotava, se obliga por contrato a Cristóbal de Ponte para cocerle una hornada de cal en la calera y horno que este último poseía junto a su ingenio de Grachico, situado debajo de los riscos de la comarca de la Culata, en el lugar que hoy ocupa la parte alta de la hacienda de el Lamero (Velázquez, 2001, p. 82).

Las Caleras de la Rambla en Tenerife son famosas por sus bellas petrificaciones y excelente blancura de su cal (Viera y Clavijo, 1868, p. 149).

(...) las caleras subterráneas de la Rambla y El Burgáo en Tenerife, de donde se sacan hermosos grupos de hojas (...) hallándose aquellas aguas impregnadas de una sustancia caliza, penetran por los poros de los 
ramos y de las hojas, que, arrebatadas por las corrientes, y rebalsadas en los remansos que hay bajo la tierra, se van incrustando y petrificando, sin que pierdan la configuración natural (...) estas piedras ordinariamente son apizarradas o calcáreas. Encuéntranse en las caleras de La Rambla, del Bulgaro, \&c. de Tenerife, en el barranco de Guadalupe, territorio de Teror, cerro de S. José en la ciudad de Canaria, \&c. (Viera y Clavijo, 1969, pp. 24-30).

Resultaba evidente por tanto la posibilidad de encontrar huellas de estos depósitos. Los trabajos de campo realizados por los autores de este trabajo han permitido obtener (Fig. 1) fotografías y muestras en La Rambla (El Realejo)
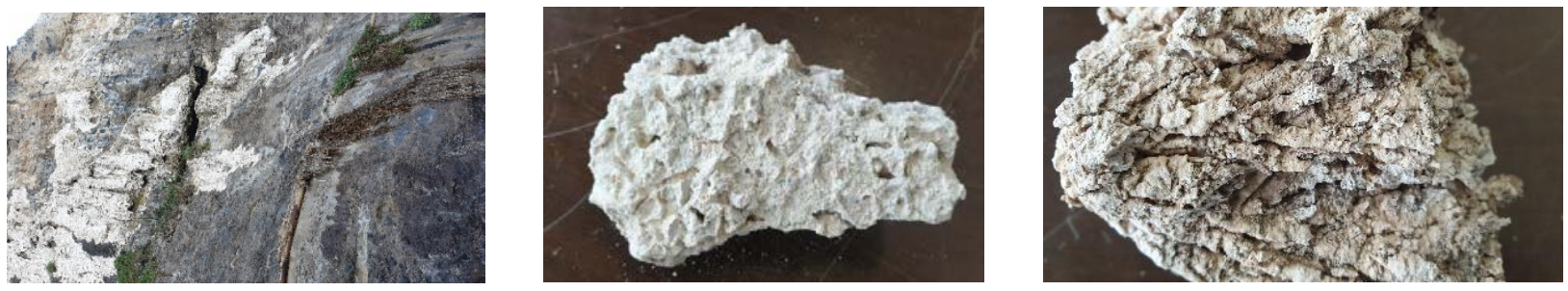

Fig. 1 Afloramiento y muestras tomadas en acantilado que separa Playa de la Fajana-Bco de la Calera (La Rambla)

El propio Fernando Martín informa también que, en 1512, “insiste el Cabildo en la carencia de este material, promocionando su extracción del lugar de Taganana, donde Pedro Fernández, portugués, declaraba haber encontrado cal” (Martín, 1978, p. 71). Los trabajos de campo no han permitido hasta ahora encontrar canteras de cal en Taganana, aunque sí en otros lugares de Anaga (Fig. 2):
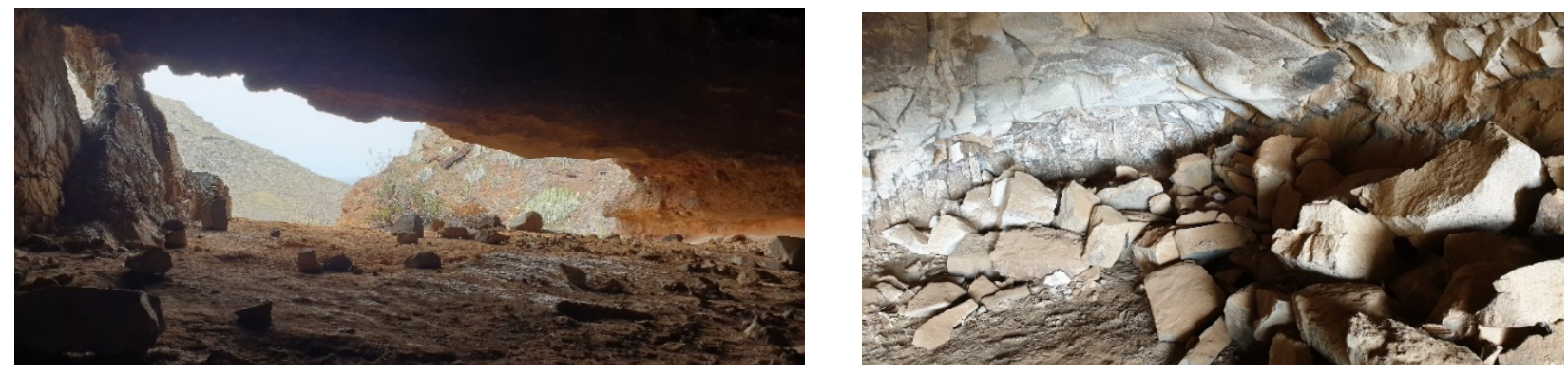

Fig. 2 Cantera-Cueva que se ubica junto al sendero que va desde Chinamada a Punta del Hidalgo

\subsection{Obtención de cal a partir de "confites"}

Aunque no deja de ser más que una posibilidad, mencionaremos un aspecto singular, documentado en la historia de Gran Canaria, que pudiera tener correspondencia en Tenerife: la fabricación de cal a partir de "confites" (Fig. 3), denominación dada a esqueletos de algas de la familia Corallinaceae. Dice Viera y Clavijo: "no hay duda de que estos confites ofrecen (...) una excelente cal para el blanqueo de las casas" (Viera, 1868, p. 235). También en Tenerife tenemos este tipo de algas: "La playa del Confital (...) En la zona de El Médano, y en particular desde la Playa de Leocadio Machado hasta la Punta de Bocinegro es muy frecuente, (...) la llegada de algas pardas (...) o rojas" (Escribano y Mederos, 2014, pp. 76-78).
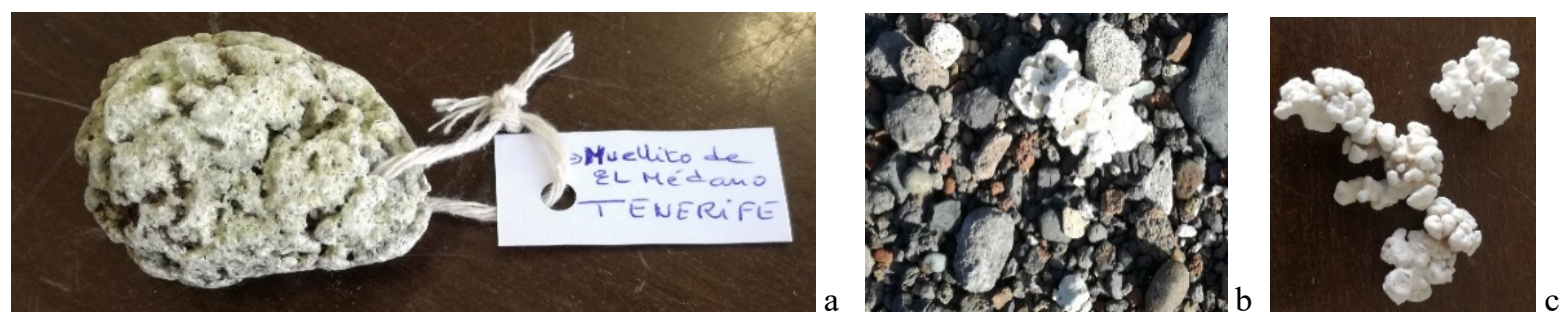

Fig. 3 Rodolitos recogidos en El Confital-Médano (a) y en Punta del Hidalgo-La Laguna (b y c) 


\section{Producción de cal a partir de agua de galerías. Horno y decantador de "Mister Villa"}

El uso de la cal, así como los hábitos de importación/cocción anotados, mantuvieron su vigencia durante más de cuatro siglos, hasta la introducción/auge progresivo de los morteros de cemento portland. No obstante, en los años cuarenta del siglo XX las dificultades de abastecimiento que surgieron a raíz de la Guerra obligaron a recuperar la cal. Coincide además este momento histórico con el auge de la agricultura de exportación, para cuyo desarrollo se avanza de manera muy significativa en la perforación de galerías para búsqueda de aguas subterráneas y en la construcción de canales tipo tajea y depósitos, conformándose una infraestructura hidráulica singular, que todavía hoy permanece.

En este contexto se lleva una experiencia de gran interés en relación con los propósitos de la investigación que nuestro G.I. viene realizando en los últimos años, cuyo objetivo es dar uso a los residuos líticos depositados por las aguas de algunas galerías y los que pudieran obtenerse a partir de las salmueras de rechazo de las Estaciones de Desmineralización de Aguas Subterráneas Salobres (EDAS).
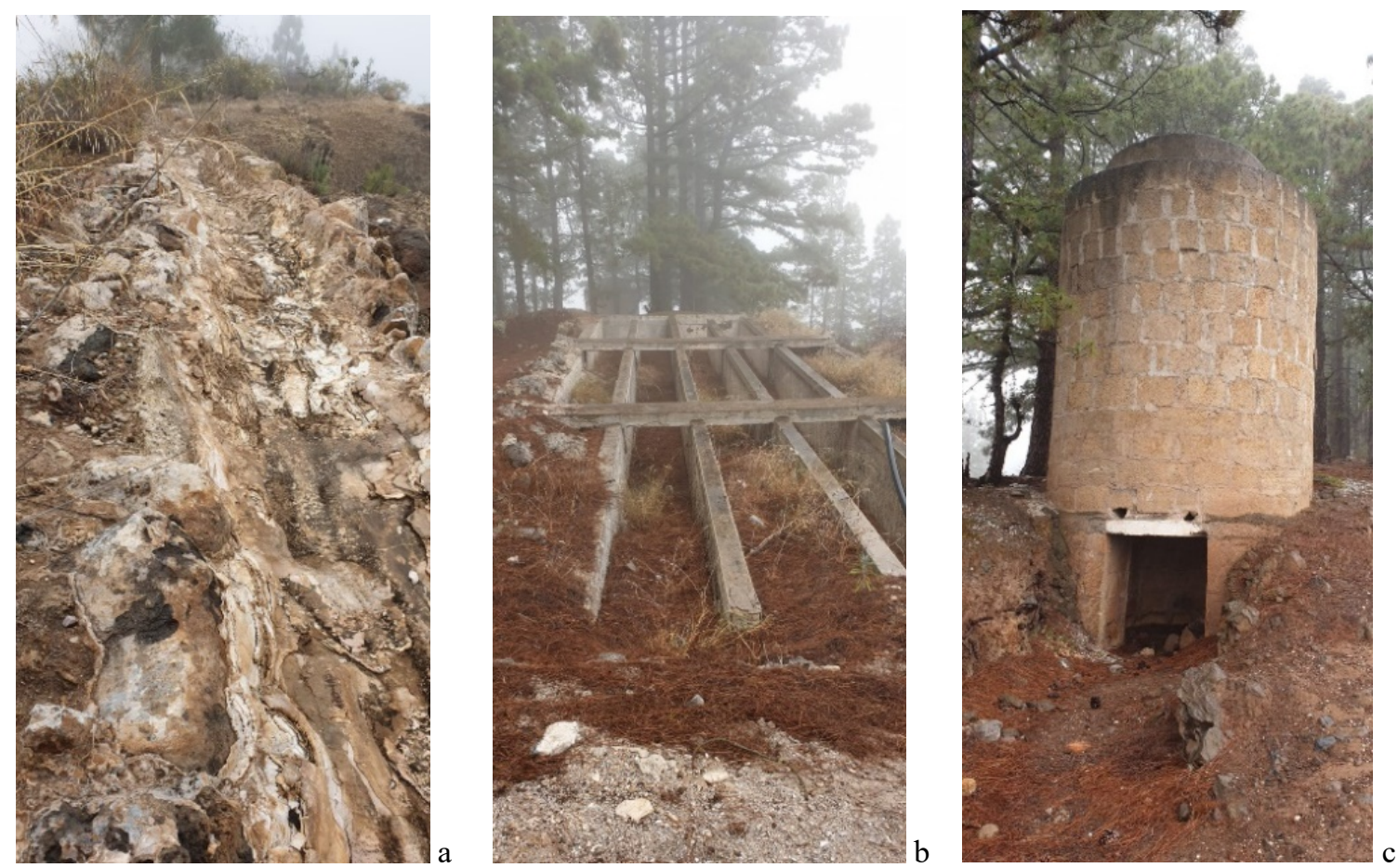

Fig. 4 Canal (a) que conducía el agua de la galería al decantador (b) y horno (c)

El horno objeto de investigación (Fig. 4), ubicado en la zona de El Bueno-Arico, a una cota de algo más de $1000 \mathrm{~m}$ y alejado de las vías principales llamó nuestra atención por su singularidad. Observamos en la parte frontal una placa en la que se lee "Horno Mister Villa". Este horno y decantador se deben corresponder con los que describe F. Sabaté:

En la década de los años cuarenta, en un contexto que apuntaba hacia la intensificación, se construyó en Arico un ingenio calero protoindustrial (...) ubicado nada menos que en la zona alta de El Bueno, a más de mil metros de altitud, y en un paraje alejado de cualquier vía rodada de comunicación (...). Ya se había observado que las aguas de algunas galerías de Arico portaban en disolución una gran cantidad de sales carbonatadas, producto de su mezcla en el acuífero con gases carbónicos vinculados a la historia volcánica de la Isla. Estas sales, además de comprometer la propia calidad del agua de riego, suponían -y siguen suponiendo en la actualidad- un problema técnico grave: al entrar en contacto con el aire, se precipitan y van formando costras calcáreas cada vez más gruesas que, si no se limpian de manera periódica, pueden acabar colmatando las conducciones. La demanda de cal y su presencia potencial en el agua que brotaba en la parte alta se fusionaron por medio de un ingenioso procedimiento: el agua se hacía pasar a través de una piscina dividida en compartimentos (a modo de serpentín) para frenar su velocidad y favorecer que las concreciones calcáreas se fueran depositando en el fondo de la cubeta. De allí se recogían, suministrando la materia prima 
(carbonato cálcico), que procedía a transformarse en cal (óxido de calcio) en un horno de gran tamaño situado un poco más abajo. Se explica así por qué los enclaves humanizados situados en las inmediaciones de ese horno (grupos de cuevas, hornos de pasar fruta, lajas impermeabilizadas para recoger agua de lluvia, pavimento de alguna era) exhiben un empleo abundante de la cal, superior desde luego a la moderación con que ésta aparece en otros ámbitos del medio rural del Sur. En fin: la lógica de esta pequeña y 'astuta' infraestructura se puede sintetizar del siguiente modo: el propio residuo que transporta el agua (las sales carbonatadas que la contaminan), se logra transformar en un recurso (la cal como material de construcción), que va a servir precisamente para construir los medios que transportan esa misma agua (Sabaté, 2011, pp. 289-290).

Los trabajos de campo realizados por los autores de este trabajo, han permitido disponer de imágenes y muestras obtenidas de la tajea, decantador y horno de "Mister Villa" y observar que se corresponden claramente con los que, cada vez en mayor proporción, deposita actualmente el agua de muchas galerías. Para evaluar el impacto, debe considerarse tanto la cantidad de residuos líticos como su progresivo aumento, Ej: según investigación de 2015-G. El Rebosadero, en los $2 \mathrm{~km}$ de conducción entre bocamina y canal general, se depositan aproximadamente 44 toneladas de piedra al año.

\section{Conclusiones}

No hay duda de que en Tenerife hubo canteras de piedra caliza y tal vez también explotación de esqueletos de rodolitos aplicados con el mismo fin, pero esos recursos, aunque hemos encontrado indicios significativos, están prácticamente agotados. Tampoco tenemos dudas sobre el hecho de que algunas de estas canteras y, en concreto las de la Rambla, debieron tener su origen en surgencias de aguas sobresaturadas en $\mathrm{CO} 2$, de tipo similar a las que hoy afloran a través de múltiples galerías del Nor Oeste y Sur Oeste de la isla. Es evidente que Mister Willian fabricó, en los años cuarenta del siglo pasado, cal de buena calidad a partir de residuos calcáreos depositados por aguas de galerías ubicadas en Arico.

Los materiales calcáreos fósiles están prácticamente agotados, pero la sobreexplotación del acuífero lleva al aumento progresivo de depósitos de tipo similar, considerados residuos y que actualmente van directamente al vertedero. Según datos del Consejo Insular de Aguas de Tenerife "El Cabildo tiene contabilizadas 1520 excavaciones en el subsuelo de Tenerife para la obtención de agua (1.122 galerías y 398 pozos) de las cuales sólo el 41\% (482 galerías y 196 pozos) suministran agua, proporcionando el $84 \%$ de este recurso básico para toda la población y aportando una media de $148,85 \mathrm{hm}^{3} /$ año (censo 2015) (...) elevada salinidad de las captaciones" (https://www.aguastenerife.org/, 1/02/ 2020).

La cal, por sus características, se ajusta plenamente a los criterios de sostenibilidad, aporta ventajas para construcciones bioclimáticas y, en el caso concreto que planteamos, está en concordancia con criterios de economía circular, ya que se podría obtenerse de formaciones residuales asociadas a la extracción/transporte/tratamiento de aguas subterráneas dando uso a un producto local que en la actualidad tiene consideración de residuo, sin utilidad alguna.

Nuestro G.I. investiga esta y otras aplicaciones de esas rocas singulares que hace cinco años denominamos como "piedras del agua" (http://riull.ull.es/xmlui/handle/915/7158) y hoy sabemos son tobas-travertinos, con prestaciones que de cara a la fabricación de cal son similares a las que ofrecen las calizas fósiles.

\section{Referencias}

Argano, S. (2009). Cal aérea en pasta, Apuntes para su buen uso. Barcelona: Juntament amb M. Guixeras, Joystuc.

Escribano, G., y Mederos, A. (2014). Prospección arqueologica de Montaña Roja y las bahías de El Médano y El Confital-La Tejita (Granadilla, Tenerife, Islas Canarias. Canarias Arqueológica, 20, 63-118.

Guixeras, M., y Argano, S. (2010). La cal: tradición del pasado e innovación hoy. Guía del Habitat ecológico. Barcelona: EcoHabitar.

González, E., y Marrero, M. (1958). Protocolos del escribano Hernán Guerra, La Laguna 1508-1510. La Laguna: Instituto de Estudios Canarios.

Larraz Mora, A. (1998). La vivienda en Tenerife a raíz de la Conquista. Los sistemas constructivos. En XII Coloquio de Historia 


\section{Canaria, Casa de Colón, Gran Canaria.}

Martín Rodríguez, F. (1978). Arquitectura doméstica en Canarias. Santa Cruz de Tenerife: Cabildo-Aula de la Cultura.

Morales Padrón, F. (1974). Ordenanzas del Concejo de Gran canaria (1531).Transcripción y estudio. Gran Canaria: Cabildo Insular.

Rumeu de Armas, A. (1975). La conquista de Tenerife: 1494-1496. Santa Cruz de Tenerife: Cabildo Insular.

Sabaté, F. (2011). El país del pargo salado. Naturaleza, cultura y territorio en el Sur de Tenerife (1875-1950). La Laguna: Instituto de Estudios Canarios.

Sanchez Bonilla, M. I. (2015). Las «piedras del agua». Posibilidades escultóricas y propuesta ambiental. En V Simposio Virtual Internacional Valor y Sugestión del Patrimonio Artístico y Cultural. Universidad de Murcia,Murcia.

Serra Ráfols, E., y De la Rosa, L. (1952. segunda edición: 1996). Acuerdos del Cabildo de Tenerife 1508-1513. Fontes Rerum Canariarum V. San Cristóbal de La Laguna: Instituto de Estudios Canarios.

Velázquez Méndez, J. (2001). La caleta de Interián (una aproximación a su historia). San Cristóbal de La Laguna: Ayto. de Garachico y Ayto. de Los Silos, conjuntamente.

Viera y Clavijo, J. (1868 el Tomo I, 1869 el Tomo II. Edición de 1942). Diccionario de historia natural de las Islas Canarias o indice alfabético descriptivo de sus tres reinos, animal, vegetal y mineral. Santa Cruz de Tenerife: Imprenta Valentí. 